Research Paper

\title{
GENIUS KIDS: Learn to Count through Games
}

\section{Wan Amirah Najwa Wan Idris ${ }^{1}$, Hanasrullah Halim ${ }^{1}$, Haslina Hassan ${ }^{1}$, Ismail Yusuf Panessai $^{1}$}

${ }^{1}$ Program of Game Development, Department of Computing, Faculty of Arts, Computing, and Industry Creative. Universiti Pendidikan Sultan Idris, Malaysia.

Article History

Received:

15.07.2019

Revised:

23.08.2019

Accepted:

05.09.2019

*Corresponding Author:

Wan Amirah Najwa Wan Idris Email:

wanamirahnajwa@gmail.com

This is an open access article, licensed under: $\mathrm{CC}-\mathrm{BY}-\mathrm{SA}$
Abstract: The goal of learning to count addition, subtraction, multiplication and division can have a positive impact for student to play because it can attract student to prefer learn while playing. The motivations for the player to play the game are interesting and not bored because this game is concept education. The aim of this research is to help students learn and love mathematics well. The objective of this research is to train student to play while counting. Researcher use use a game maker to develop this game and adobe photoshop for design. Researcher use a game maker to develop this game and adobe photoshop for design. The first idea of this game is not to make a fire, but wants to make the player jump to touch a block that contains a question mark so that it will reveal either poison or medicine. If medicine, Ben has extra point but if poison, he must to answer the question again. However, the idea is further expanded to make the barrier because the game is only for children aged 12 and below. Problem software development when compile many error at the system and must to reduce unimportant views and display size resolution because of the many elements causing game maker to run. The suggestion for this game is screens need to be raised to attract children to plays.

Keywords: Counting, Educational Game, Instructional Technology. 


\section{Introduction}

The learning goal of learning to count addition, subtraction, multiplication and division can have a positive impact for student to play because it can attract student to prefer learn while playing. Children acquire digital literacy informally, through play, and neither schools nor other educational institutions take sufficient account of this important aspect. In recent years, electronic games have assumed an important place in the lives of children and adolescents. Children acquire digital literacy informally, through play, and neither schools nor other educational institutions take sufficient account of this important aspect [1]. The motivations for the player to play the game are interesting and not bored because this game is concept education.

The aim of this research is to help students learn and love mathematics well. The extent of the area or subject matter that something deals with or to which it is relevant. The scope in this game is designing and development on pc windows 10 . Then, game are to have a platform and education style of gameplay.

After that, the minimum of two playable character and obstacle. Lastly, three slightly different background images that can be expended in several possible game levels [2].The objective of this research is to train student to play while counting.

\section{Methodology}

Researcher a game maker to develop this game and adobe photoshop for design.

\subsection{Game Overview}

There are some about GENIUS KIDS:

- Genre

Platform and Education because this game about Ben need to answer the mathematics question.

\section{- Target Demographic}

8 until 12 years old old because the question at each level just basic mathematics only.

- Hight Concept

Excellent in exams because Ben must make his parents proud with him.

- Unique Selling Point (USP)

Factor that diffenties a product from its competitors, such as the lowest cost, the highest quality ot rhe or the first-ever product of its kind. A USP could be though of as "what you have that competitors do not". This game has different mathematical questions for each level. Then, can be gradute when he successfully answered questions from level 1 until level 3. After that, there is an interesting envelope that contains the questions.

\section{- Game Mechanics}

The formal rules that define the operation of the game world, what the player can do, the challenges the player will face, and the player's goals and also in relation to rules and challenges. Game mechanics are methods invoked by agents for interacting with the game world [2]. This game is player_must be to answer all the question in each level to score. Therefore, player need to jump and touch the box that contains a question mark so that it will reveal either poison or medicine. Then, players also need to enter the open door to graduate.

\section{- Platform and Minimum Specifications}

The platform defines a standard around which a system can be developed. Once the platform has been defined, software developers can produce appropriate software and managers can purchase appropriate hardware and applications. The term is often used as a synonym of operating system. This game I'm use Pc because easy to children below 12 years old play this game on a large screen. It also player also easy to control rules of the game. Then, attention to showing that video "game" action and computer games have a positive impact to heighten the visual selective attention of the student. But the discovery is just a small part of the more important message that all parents and educators need to hear [3]. Lastly, it easy for PC gaming to have better graphics.

\subsection{Storyline}

The storyline of the game is important as it is kept the user or the student playing on the game, to know what will happen next. Ben game has an examination which is just around the corner [4]. Threfore, he needs to do some revisions on mathematic exercise since he got a bad grade for his mathematics subject in the previous exam. 
Wan Amirah Najwa Wan Idris, Hanasrullah Halim, Haslina Hassan, Ismail Yusuf Panessai.

Storyboard of this game is shown in Figure 1.
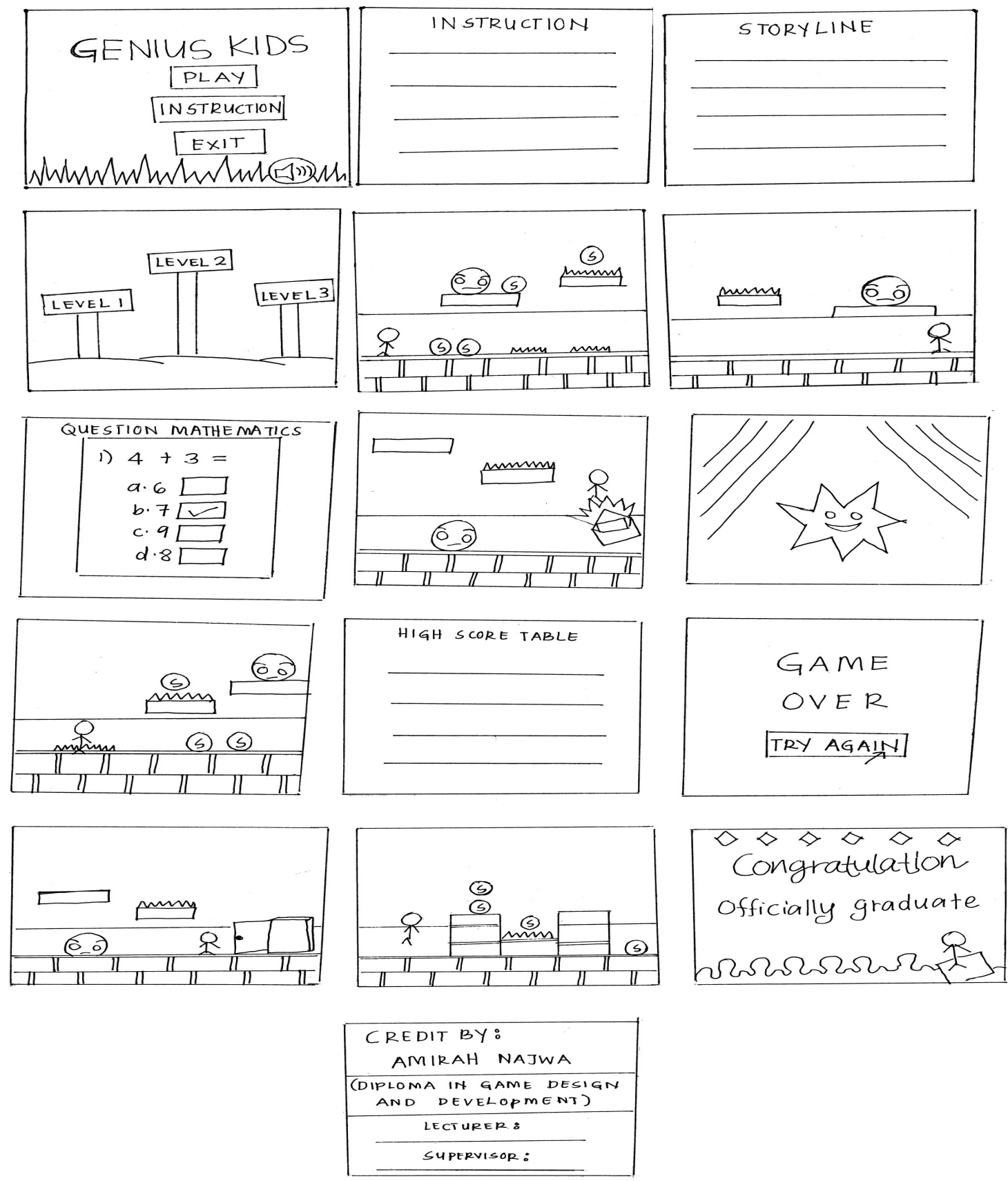

Figure 1. Storyboard

\subsection{Game Design}

\subsubsection{Concept and Style}

The art style refers to the look of the game. Downwards there are a few explanations of the way the art style would be done, afterward some images from other games which would give a glimpse towards the art style of the game. The environment in this game shows a place in the jungle from level 1 to level 3 where the player must escape from the enemy and obstacle to successfully open the envelope. 


\subsubsection{Colors}

The characteristic of human visual perception described through color categories, with names such as red, orange, yellow, green, blue, or purple [5]. This perception of color derives from the stimulation of cone cells in the human eye by electromagnetic radiation in the visible spectrum [6]. Color categories and physical specifications of color are associated with objects through the wavelength of the light that is reflected from them.

Colors are available in level 1 is light green environment where player will calm down with interesting sights to play. Next, the environment in level 2 is bright green in which the player is in the middle of the goal and save yourself from enemies. While the color environment in level 3 is blue, where blue represent the imagination, the main source of the game and the player should be more excited to succeed.

\subsubsection{Character Design}

There are two character in this game, namely:

1. Ben character

2. Enemy character

\subsubsection{Ben Character}

In this game, Ben as Main character. Ben a primary school student who has the principle of life to succeed in the exams so as to be proud of his parent. However, he was determined to do some exercise so he could have a brilliant decision in exams. Animation characters for the right side is shown in Figure 2. and animation characters for the left side is shown in Figure 3.
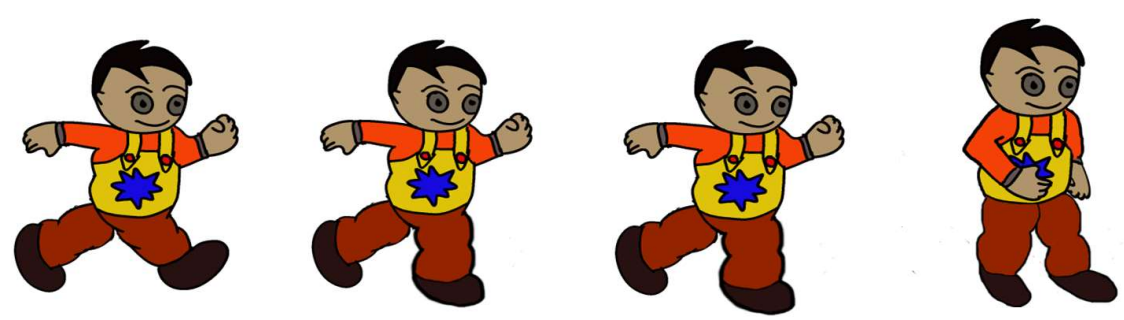

Figure 2. Animation Characters for the Right Side
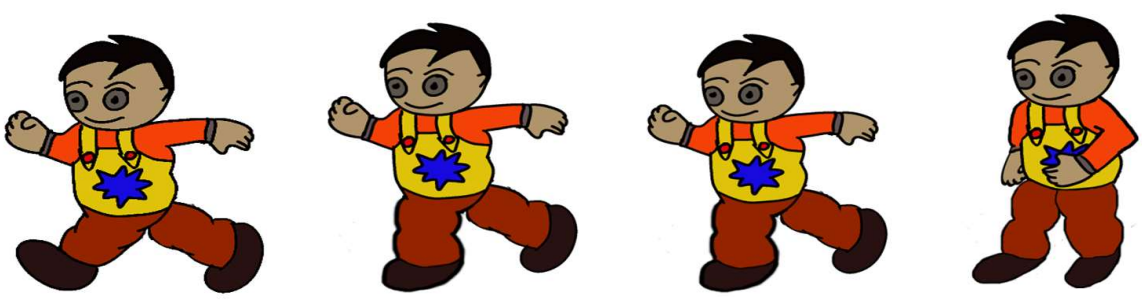

Figure 3. Animation Characters for the Left Side

Characters for the font side is shown in Figure 4, and characters graduate is shown in Figure 5.

\subsubsection{Enemy Character}

Simon is an enemy and will disturb Ben to do some exercises until he give up for learns is shown in Figure 6 . 


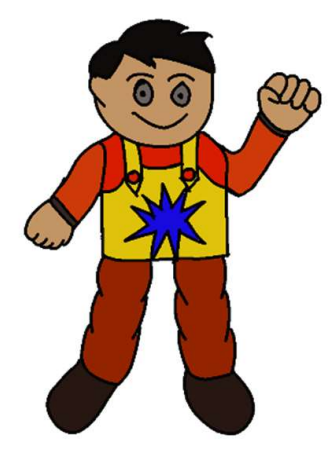

Figure 4. Characters for the Font Side

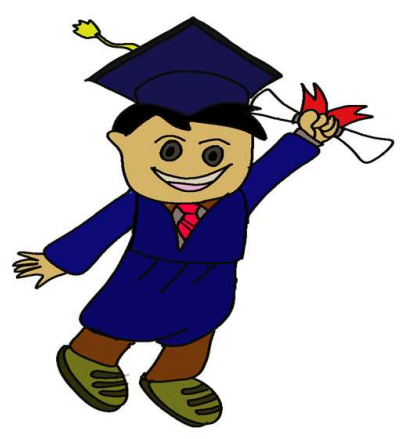

Figure 5. Characters Graduate

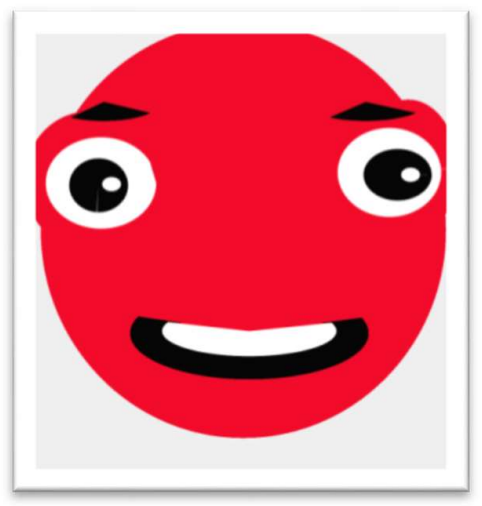

Figure 6. Characters: Simon

\subsubsection{Environment and Scene Design}

Environment and scene design for level 1, environment and scene design for level 2, environment and scene design for level 3, and environment and scene design for graduation day are shown in Figure 7, Figure 8, Figure 9 and Figure 10. 


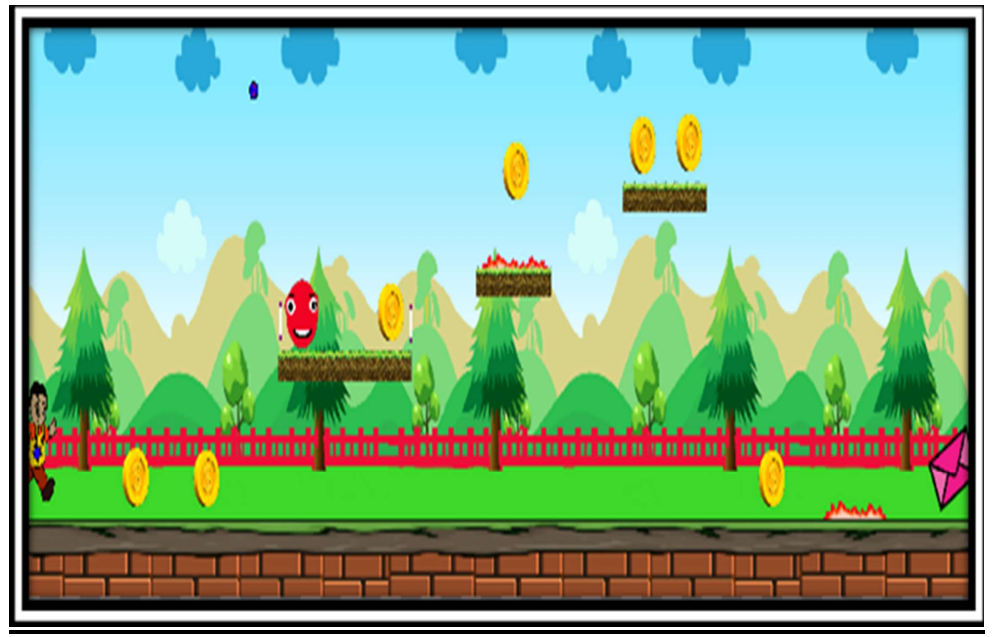

Figure 7. Environment and Scene Design for Level 1

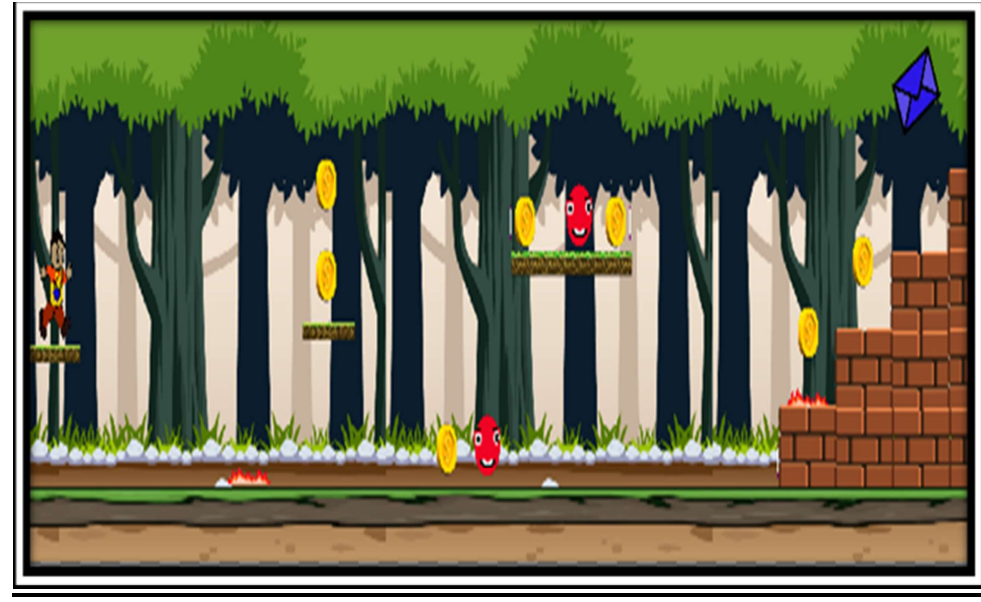

Figure 8. Environment and Scene Design for Level

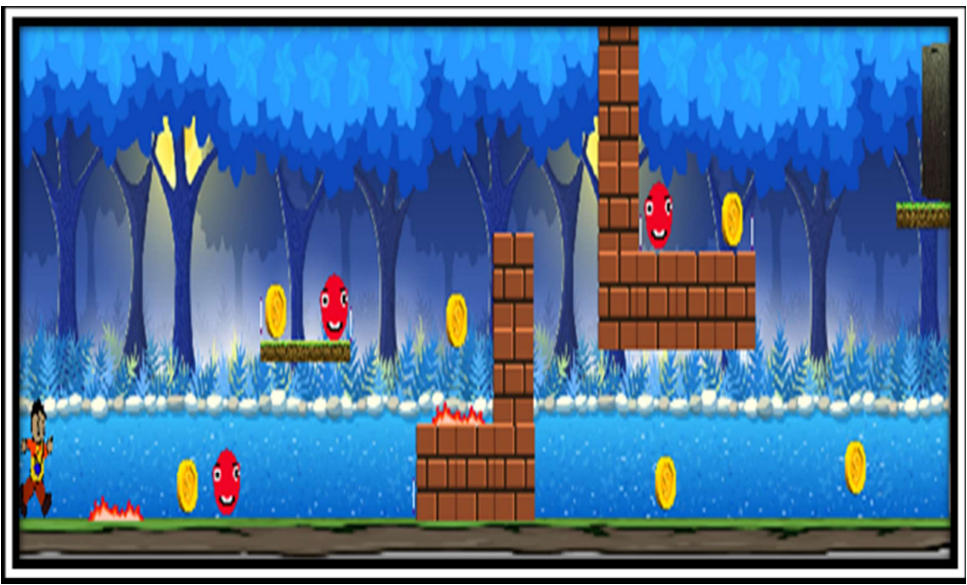

Figure 9. Environment and Scene Design for Level 3 


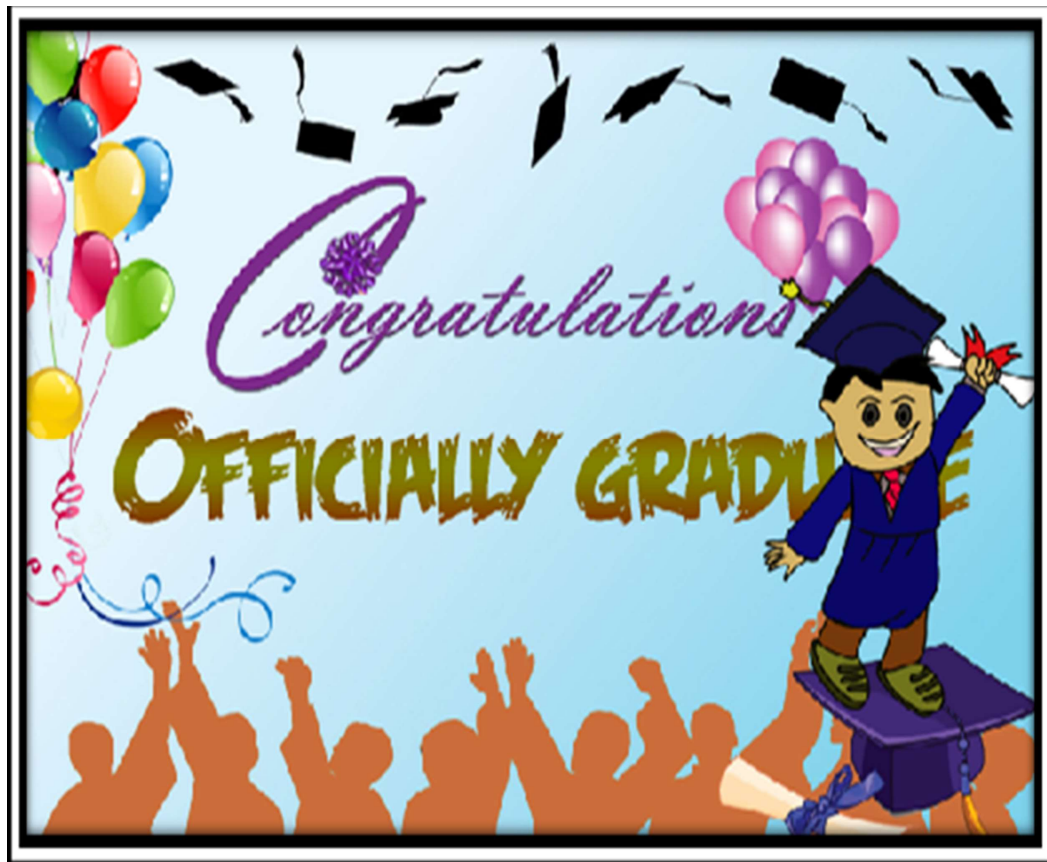

Figure 10. Environment and Scene Design for Graduation Day

\subsection{Game Development}

\subsubsection{Programming or Authoring}

This stage is a way to make every object in this game. The created object consists of Object Play, Instruction, Exit, Sound, Fire, Coin, Enemy, Jump Platform, Boxes, Platform, Open Envelope, Level, Lives, Score, High Score Table, Control, Next, Getname, Continue, Touch Me, Try Again, Right, Wrong, Close Door and Open Door. The following is an example of the appearance when creating an object shown in Figure 11.

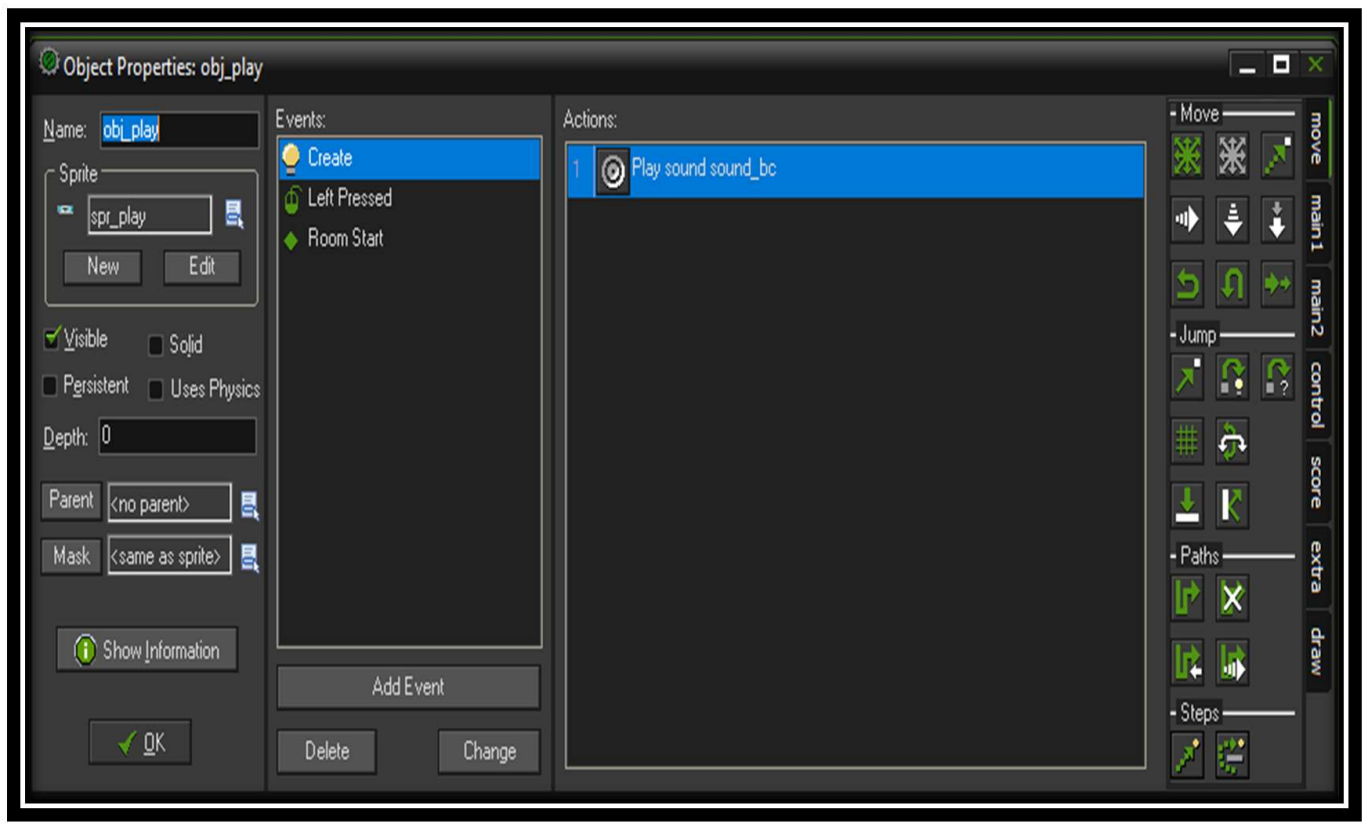

Figure 11. Object Play 


\subsubsection{2-Dimension}

This game is 2D. The screenshot of the GENIUS KIDS game can be seen in Figure 12.

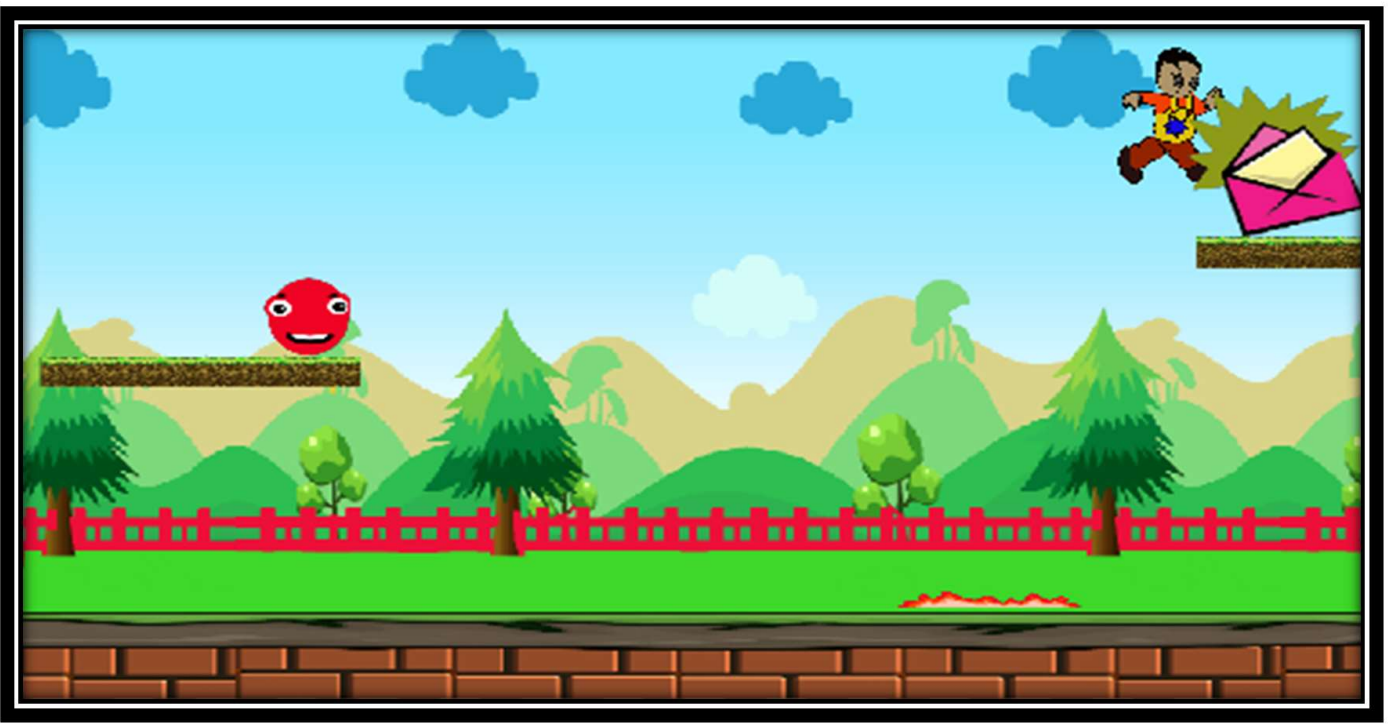

Figure 12. Genius Kids Game Screenshoot

\subsubsection{Software Used}

There are some software used to develop this game, include:

1. Adobe Photoshop

2. Gimp

3. Microsoft Word

4. Power Point

5. Audacity

6. Game Maker

Adobe Photoshop is the software that used for design environment and all. Gimp is the software that used for design character [7]. Microsoft Words is the software that used for documentation in this game. PowerPoint is the also software that used for documentation in this game. Audacity is software that used to improve and minimize sound [8]. Game maker is the engine that used to develop this game [9].

\subsection{Game Play}

\subsubsection{Game Play Element}

There are some game play elements:

- Figure 13 shows game front.

- Figure 14 shows storyline.

- Figure 15 shows inctruction.

- Figure 16 shows continue instruction.

- Figure 17 shows continue instruction.

- Figure 18 shows level.

- Figure 19 shows level 1.

- Figure 20 shows level 2.

- Figure 21 shows level 3.

- Figure 22 shows high score

- Figure 23 shows game over

- Figure 24 shows graduation day

- Figure 25 shows credit by 


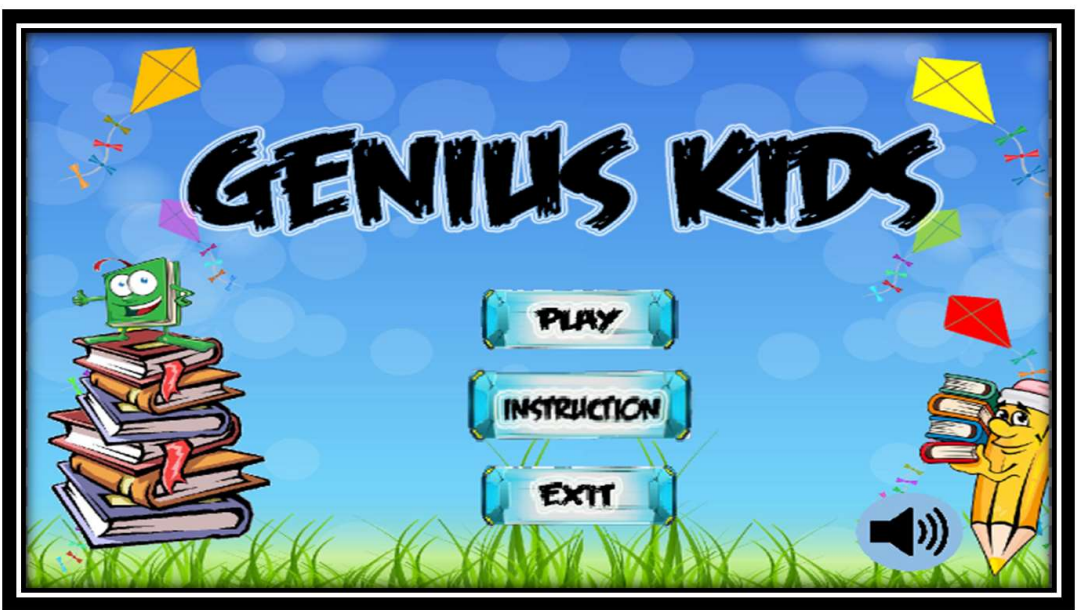

Figure 13. Game Front

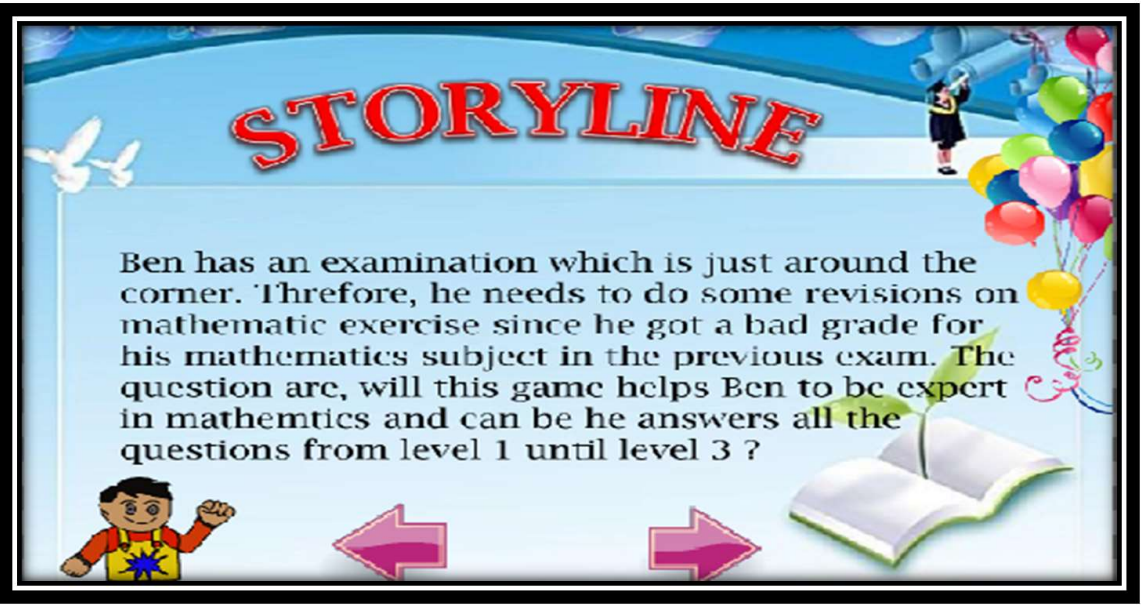

Figure 14. Storyline

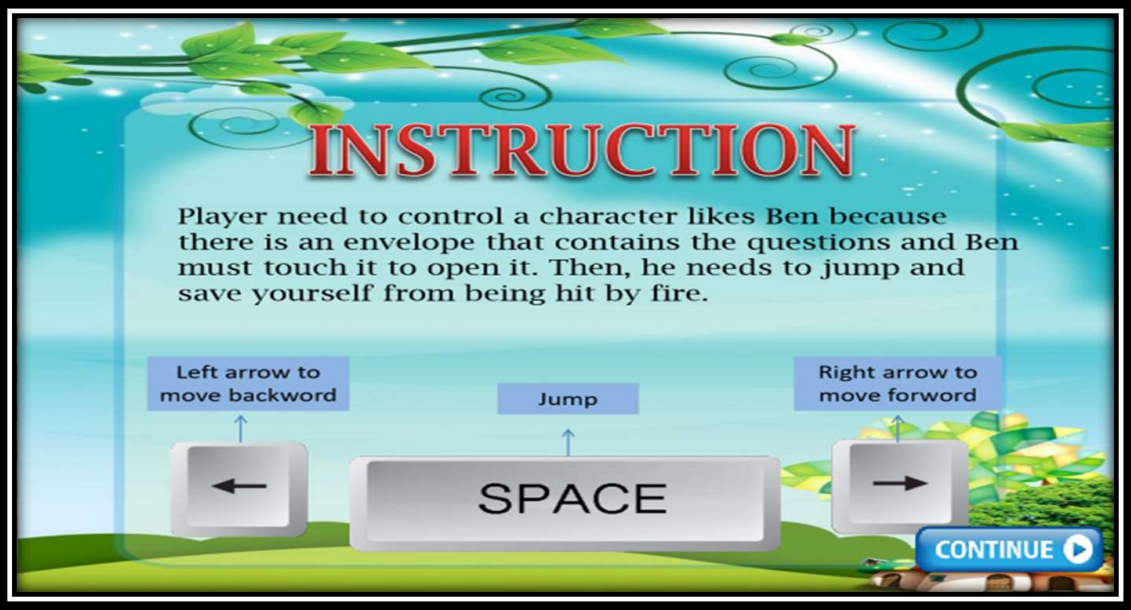

Figure 15. Instruction 


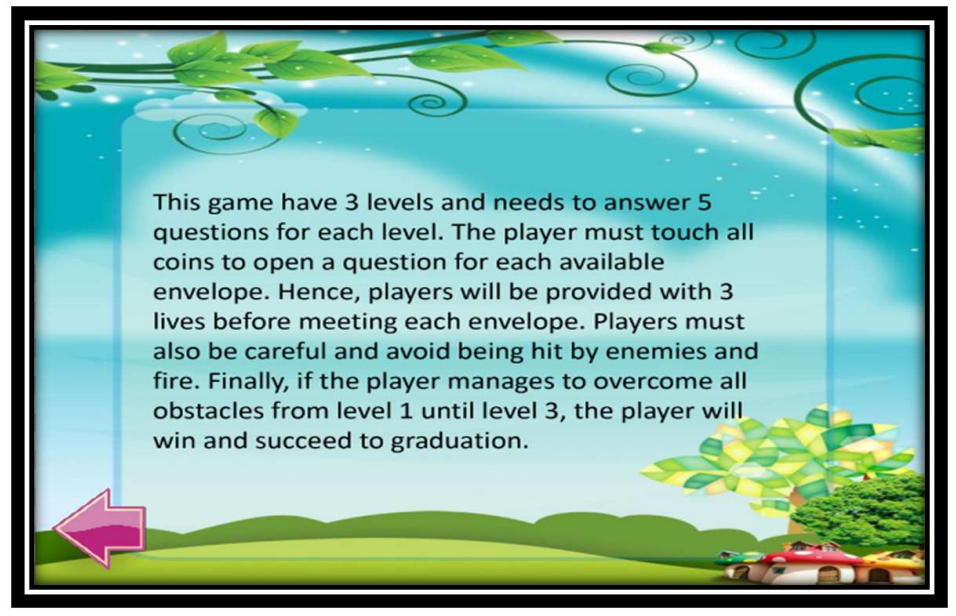

Figure 16. Continue Instruction

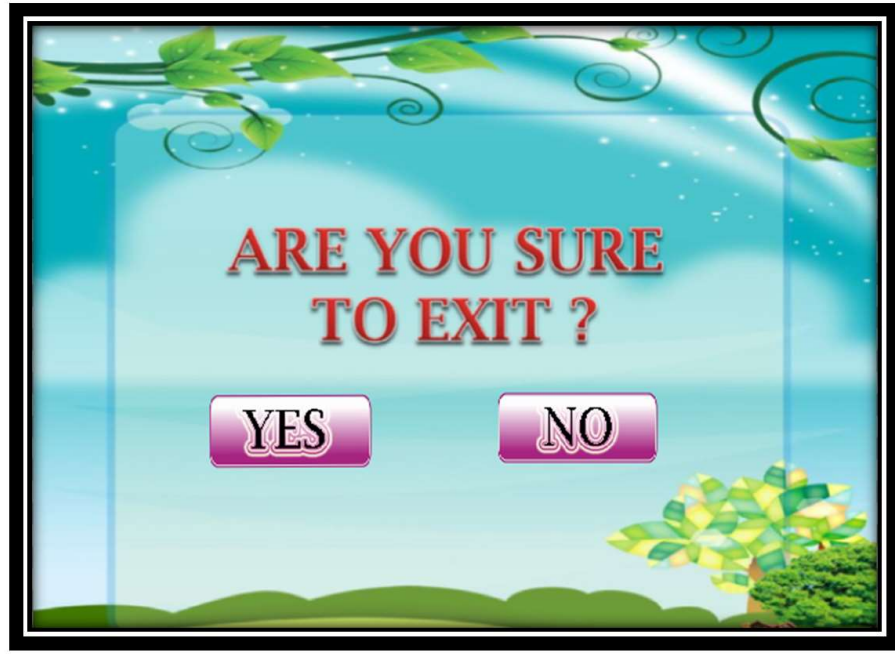

Figure 17. Continue Instruction

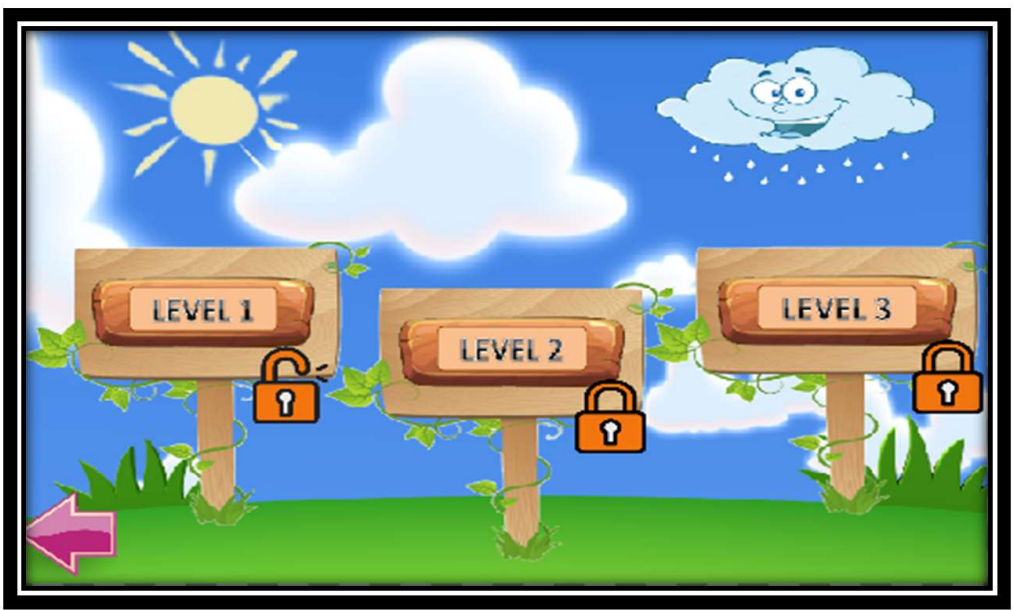

Figure 18. Level 
Wan Amirah Najwa Wan Idris, Hanasrullah Halim, Haslina Hassan, Ismail Yusuf Panessai.

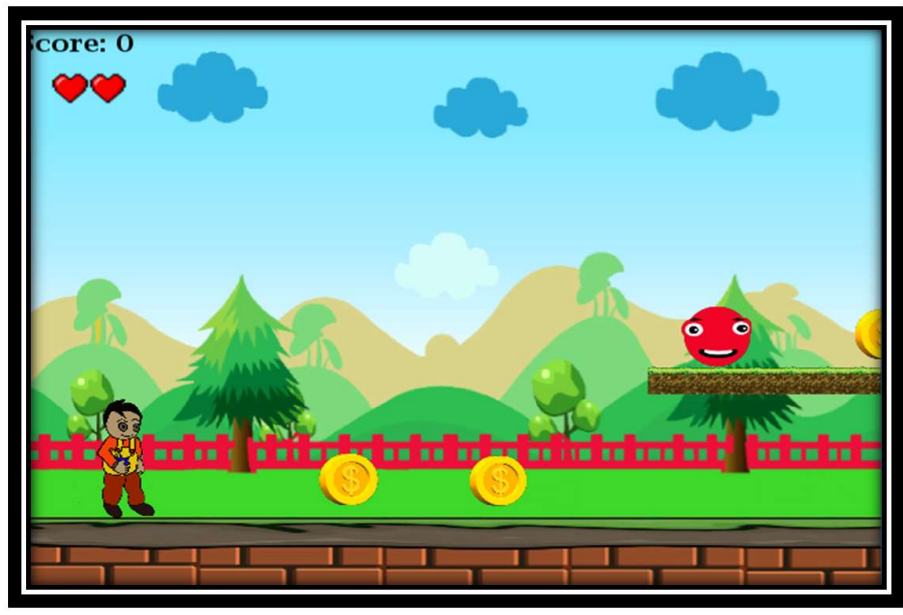

Figure 19. Level 1

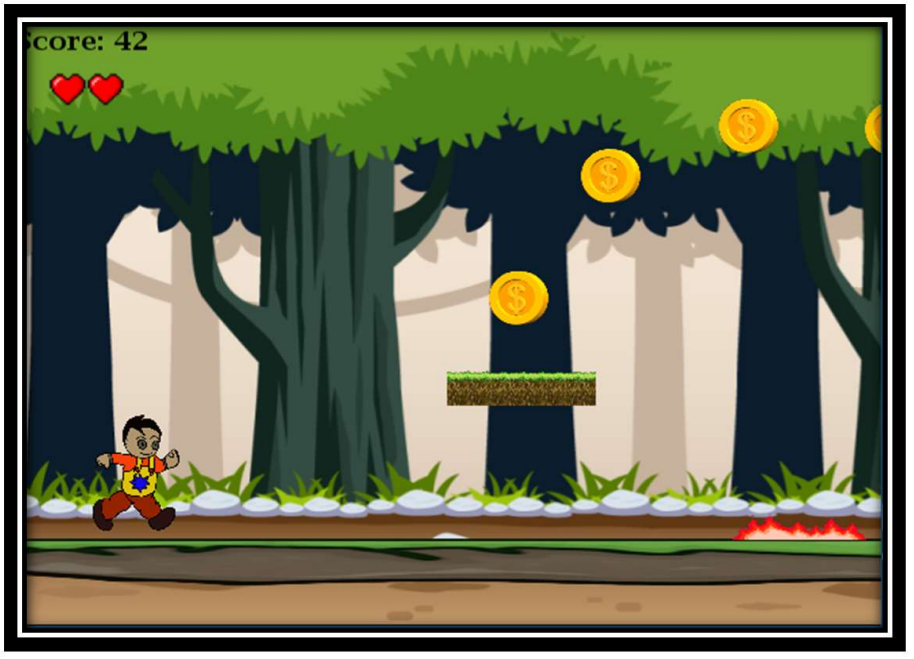

Figure 20. Level 2

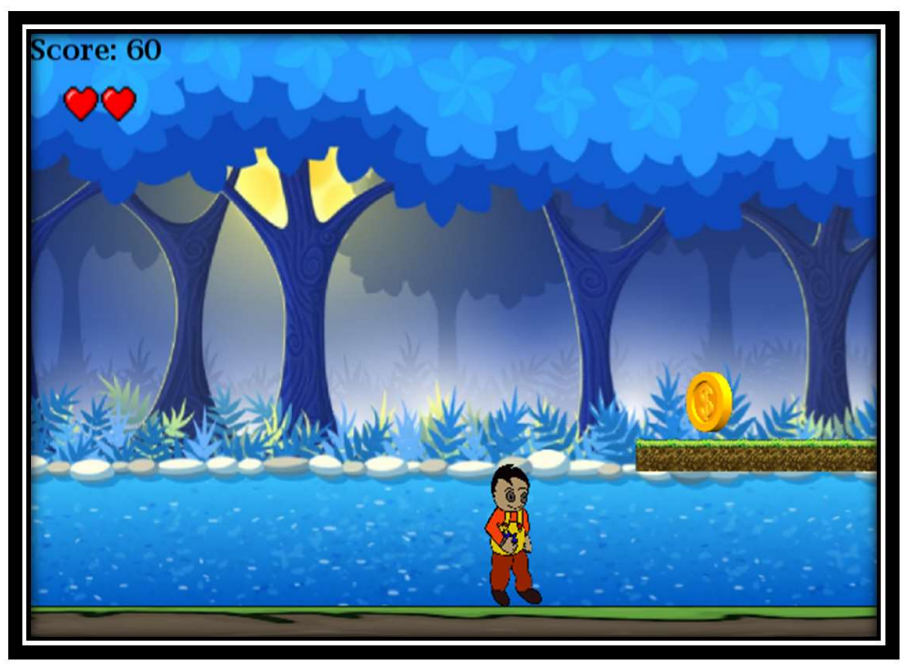

Figure 21. Level 3 
Wan Amirah Najwa Wan Idris, Hanasrullah Halim, Haslina Hassan, Ismail Yusuf Panessai.

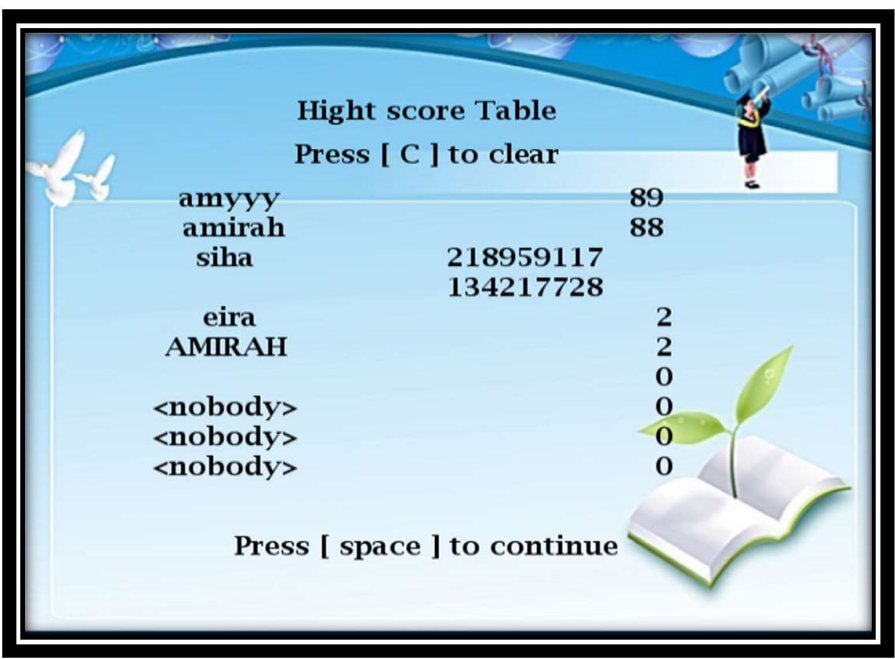

Figure 22. High Score

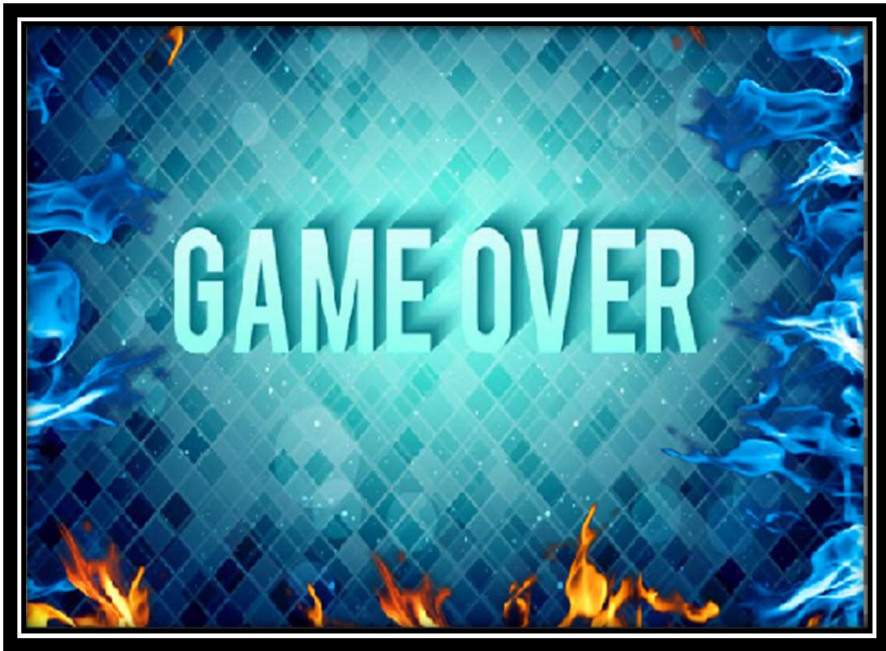

Figure 23. Game Over

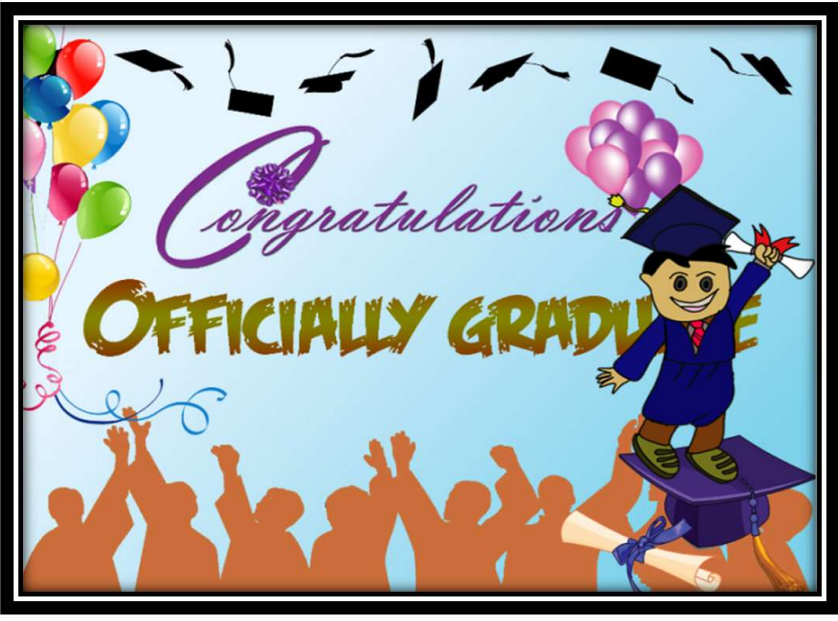

Figure 24. Graduation Day 


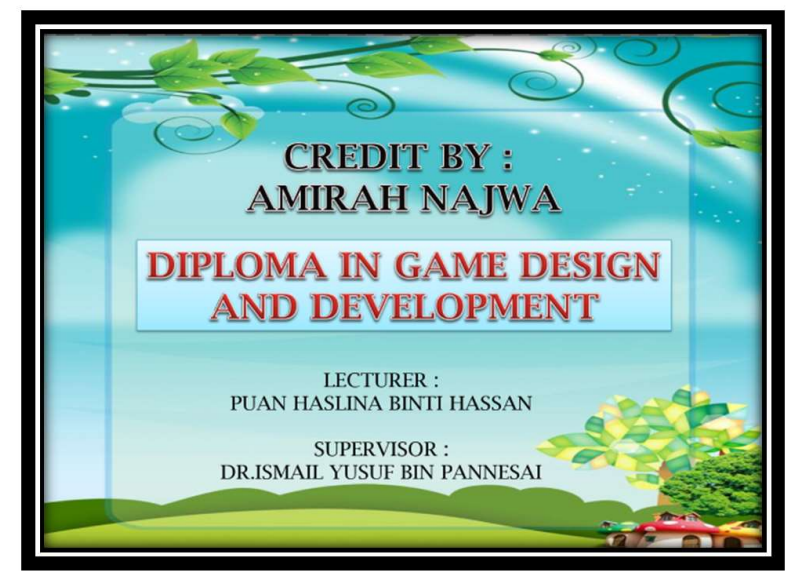

Figure 25. Credit By

\subsubsection{Game Pacing}

The game has three different levels where each level has a stage from low to high. Hence, there a obstacle and enemies that are growing and player need to save themselves.

\subsubsection{Rewards}

The rewards is something are the benefits that you receive as a result of doing or having that thing. For this game if the player can answer the question, the player can get the star. Then, If the player succesfull avoid from enemy,the player can continue the game. Lastly, If the player can collect all the coins, the envelope will open.

\subsubsection{Penalties}

A punishment imposed or incurred for a violation of law or rule of the game. Such as, in this game, if the player cannot answer the question, the player must will repeat again the question. Then, if the player cannot succesful avoid from enemy, this game can be game over.Lastly, if the player cannot collect all the coins, the envelope will not open.

\subsubsection{Mission}

Short statement of why an organization exists, what its overall goal is, identifying the goal of its operations. The game's mission is the player will need to answer all questions from level 1 until level 3 to graduate at the end of the game.

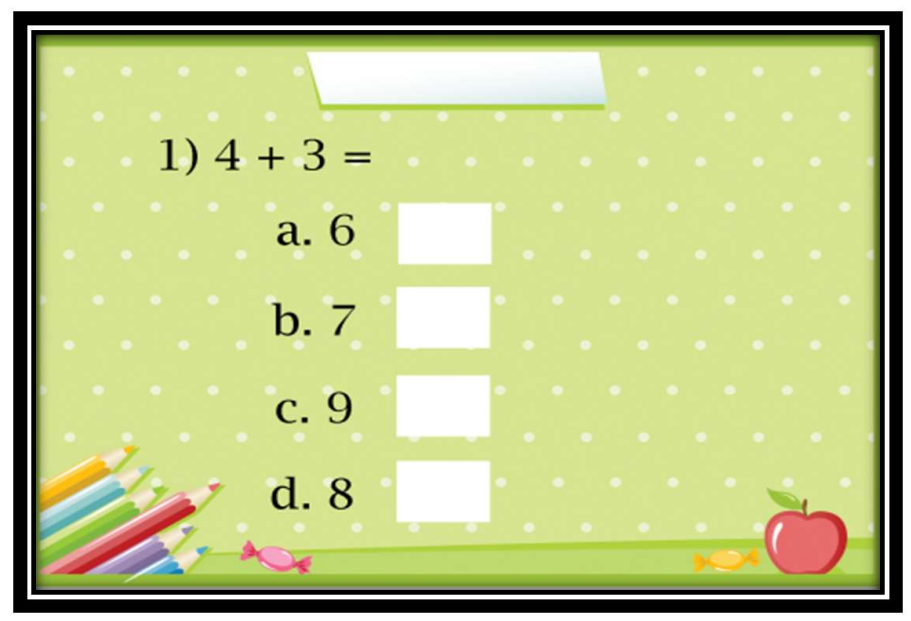

Figure 26. An Example of Question at Level 1 


\subsubsection{Levels}

This game has 3 level and each level has 5 questions. Then, have numbers of different enemies and obstacle. After that, each level also has 42 coins and has door to go the next level. In level 1, player need to answer the addition and subtraction question. While, in level 2, player need to answer the addition, subtraction and multiplication question. Lastly, in level 3, player need to answer the addition, subtraction, multiplication and divison question.

Figure 26 shows an example of question at level 1, and Figure 27 shows an example of question at level 2 while Figure 28 shows an example of question at level 3.

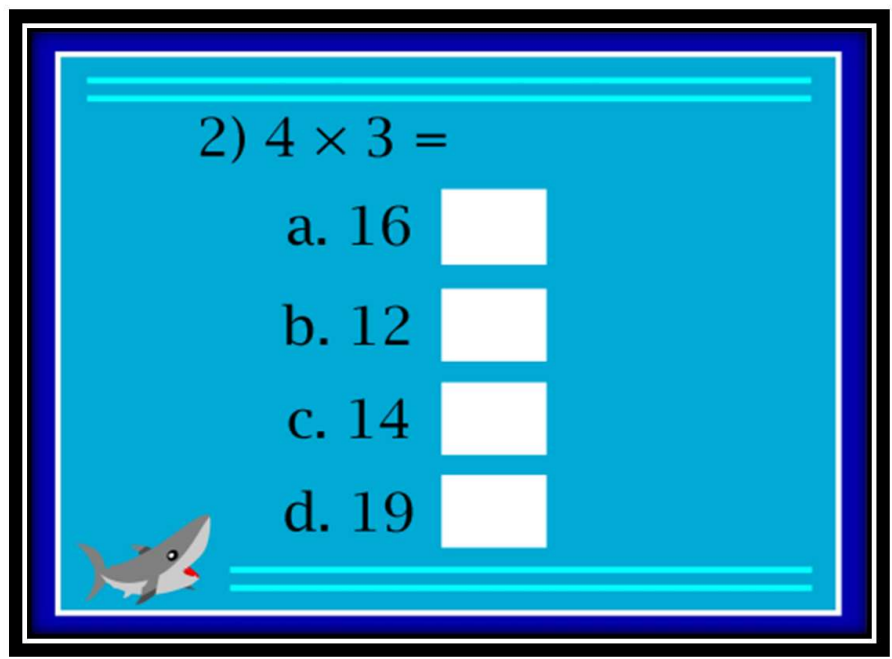

Figure 27. An Example of Question at Level 2

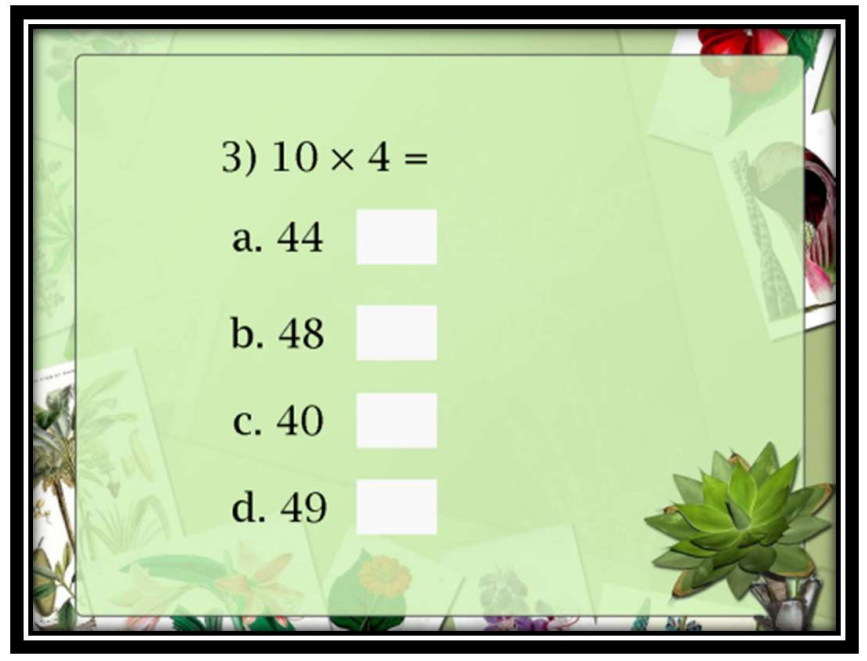

Figure 28. An Example of Question at Level 3

\subsection{Interface and Interaction}

2.6.1. Game Flow Diagram

Figure 29. shows game flow diagram. 


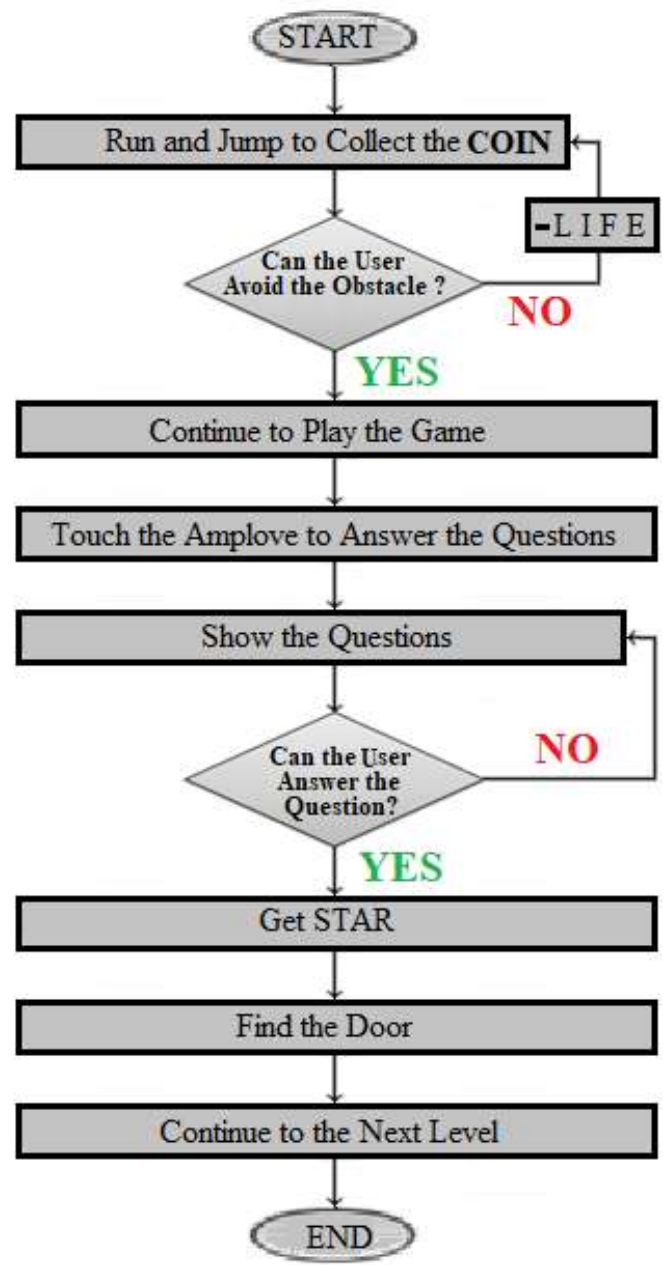

Figure 29. Game Flow Diagram

\subsubsection{Screen Flow Diagram}

Figure 30. shows screen flow diagram.

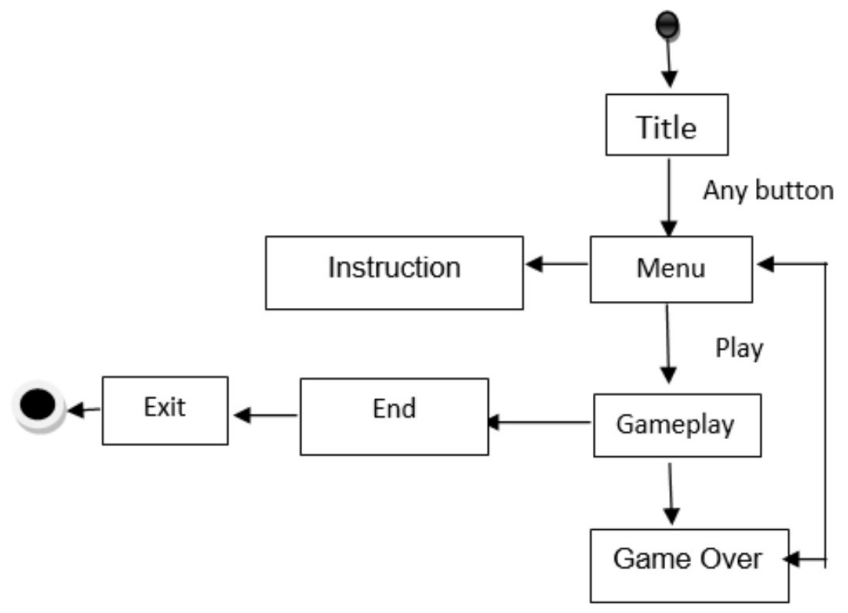

Figure 30. Screen Flow Diagram 


\section{Result}

Video games are complex, emergent systems that are difficult to design and test.This difficulty invariably leads to failures being present in the game, negatively impacting the play experience of some coding error in a computer program [10]. The bugs in this game is player must jump first before walking. Then, unable to set character not to fly. Lastly, players too much pressing 'space' to jump cause gravity easily fall and players get bored to play.

\subsection{Gamer's Feedback}

Figure 31 shows gamer's feedback. $80 \%$ user said playing GENIUS KIDS is interesting.

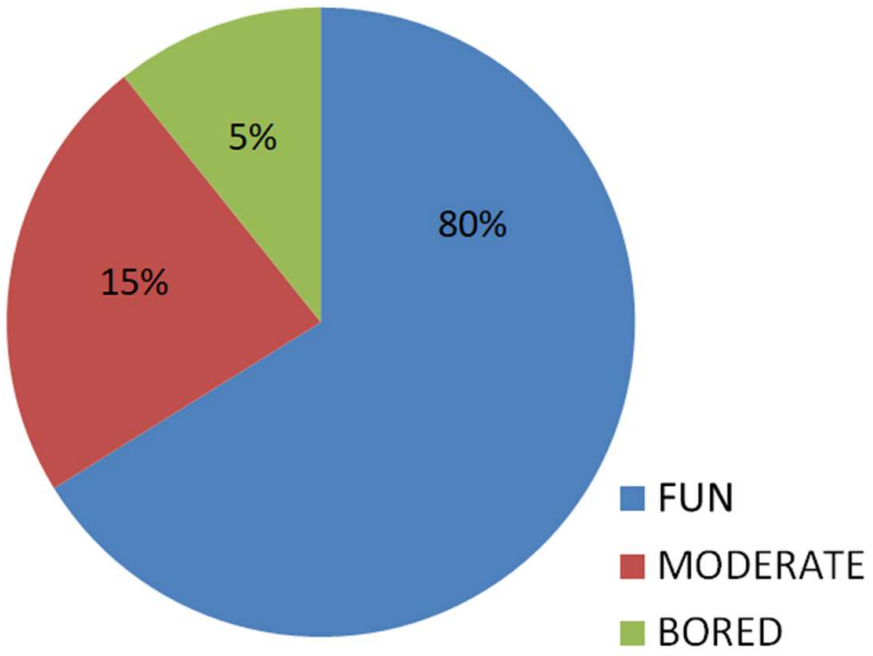

Figure 31. Gamer's Feedback

\section{Disscusion}

\subsection{Unexpected Feautures}

The first idea of this game is not to make a fire, but wants to make the player jump to touch a block that contains a question mark so that it will reveal either poison or medicine. If medicine, ben has extra point but if poison, he must to answer the question again. However, the idea is further expanded to make the barrier because the game is only for children aged 12 and below.

\subsection{Problems Faced}

Problem software development when compile many error at the system and must to reduce unimportant views and display size resolution because of the many elements causing game maker to run.

\section{Conclusion}

The suggestion for this game is screens need to be raised to attract children to play. Then, enlarge the spark so clear and players are more sensitive and careful. Therefore, if a player loses to level 3, the player does not need to play the game from level 1, but players need to repeat level 3 only. Lastly, put some attractive things in this game.

\section{References}

[1] G. Begoña, "Digital Games in Education: The Design of Game-Based Learning Environments, " Journal of Research Technology Education, vol. 40, pp. 1-21, 2006.

[2] M. Sicart, "Defining Game Mechanics," The International Journal of Computer Game Research, vol. 8, no. 8, pp. 1-15, 2018.

[3] M. Prensky, "Digital Game-Based Learning," October, 2003 [Online]. Available: from https://dl.acm.org/doi/10.1145/950566.950596. [Accessed on: June 2019] 
[4] W. Y. Seng, and H. M. Y. Maizatul, "Computer Game as Learning and Teaching Tool for Object Oriented Programming in Higher Education Institution," Procedia - Social and Behavioral Sciences, vol. 123, no. 20, pp. 215-224, 2014.

[5] A. Hurlbert, "Understanding Colour Perception and Preference," Colour Design: Theories and Applications, pp. 129-157, 2012. doi: 10.1533/9780857095534.1.129.

[6] D. Brien, Life Comes in Three Parts. Indiana: Xlibris Corporation, 2019.

[7] B. L. Mitchell, Game Design Essentials. New Jersey: John Wiley \& Sons, 2012.

[8] M. Dias, C. Paulo, and D. Ventura, "How to study the Doppler effect with Audacity software," Physics Education, vol. 51, no. 13, pp. 1-6, 2016.

[9] J. Jenson, and M. Droumeva, "Exploring Media Literacy and Computational Thinking: A Game Maker Curriculum Study," Electronic Journal of e-Learning, vol. 14, no. 2, pp. 111-121, 2016.

[10] C. Lewis, W. Jim, and N. Wardrip-Fruin, What When Wrong: A Taxonomy of Game Bugs. California: University of California, 2010. 